\title{
Determination of heating value of industrial waste for the formulation of alternative fuels
}

\author{
G. Bouabid ${ }^{1, a}$, D. Nahya ${ }^{2}$ and M. Azzi ${ }^{1}$
}

${ }^{1}$ Équipe «électrochimie et chimie de l'environnement», Laboratoire Interface, Matériaux, Environnement, Faculté des Sciences de Ain Chock, BP. 5366 Maarif, Casablanca

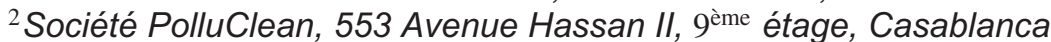

\begin{abstract}
The use of alternative fuels has become increasingly widespread. They are basically designed based on industrial waste so that they can substitute fossil fuels which start to become scarce. Alternative fuels must meet some criteria, namely an important calorific content, minimum humidity and ash content. When it comes to combustion, the most interesting parameter is the calorific value which represents the thermal energy released during combustion. The experiments that were conducted showed that the calorific value is influenced by other parameters namely moisture and ash content. It was therefore necessary to study the behavior of the heating value in terms of these two parameters in order to establish a relationship that is used to describe the behavior. This is expected to allow a simulation of the calorific value of a mixture of various industrial waste.
\end{abstract}

Alternative solid fuels are considered not only to be a solution for waste treatment but also asto be a genuine energy resource, increasingly used in various thermal treatment facilities. They are designed based on different types of industrial wastes with a dual purpose: Incineration can generate on one hand energy which allows them to be an alternative to fossil fuels, and on the other hand, their incineration preserves and protects the environment. These fuels must have adequate thermal energy which depend on the type of components and their organic content.

Alternative fuels used must meet certain criteria and must not exceed the limits of certain parameters, namely: an important calorific content, a minimum humidity and ash content, in addition to a low content in heavy metals and toxic elements.

There are four categories of ASF:

- solid biofuels (biomass waste)

- the solid recovered fuels: prepared from non-hazardous waste (household waste, industrial waste ...)

- fuels from hazardous waste (solvents, oils ...)

- specific fuels (or used pneumatic MBM).

In this work, we will present the results of tests that have been conducted on some raw materials (cardboard/paper, plastics, sewage treatment plants, charcoal...) in purpose to be used as fuel. This is why we conducted the measurement of parameters showing the following properties:

- Chemical (elemental analysis, trace element analysis, analysis of ash)

- Mechanical (bulk density, particle size, particle size distribution)

- Calorific (Heating value, adiabatic combustion, minimum volume of air required for combustion)

- Technical reaction (temperature auto ignition behavior of combustion, formation of the fouling layer ...).

a e-mail: ghizlane.bouabid@gmail.com

\section{I) EXPERIMENTAL PROCEDURE (MATERIALS AND METHODS)}

Tests that were carried out consist of the determination of calorific value, moisture content and ash content for different samples prepared earlier. In Addition to this is the study of the influence of moisture and ash on the calorific value.

\section{1) Sampling}

Sampling, sample preparation and analysis of the degree of pollution is proving to be a difficult task due to the heterogeneity of these fuels. This is why it is not easy to get a representative sample. We chose to proceed with the classification of waste as raw material groups namely cardboard and soiled paper (CP), activated carbon (AC), plastic $(\mathrm{Pl})$ and sludge generated by the treatment plants wastewater (B) [3].

The samples were dried in the oven, then ground to a particle size of $4 \mathrm{~mm}$. They are then packed in tablet form to facilitate combustion of the product in the bomb calorimeter.

\section{2) Measurement of calorific value of fuels}

The calorific value or the heating value (HV) is a physical property of all fuels. It represents the actual amount of heat in a combustion process (expressed most often in kilocalorie, kilojoule or megajoule) of one kilogram or one liter of fuel. Measuring the calorific value of fuel is performed by calorimetry (Figure 1).

We proceed in a bomb calorimeter. A mass $\mathrm{m} 1(\mathrm{~g})$ of fuel is introduced (mass between $1 \mathrm{~g}$ and $4 \mathrm{~g}$ ) in the bomb filled with enough oxygen under pressure to ensure complete combustion. The bomb is immersed in a calorimeter containing a precise amount of water 


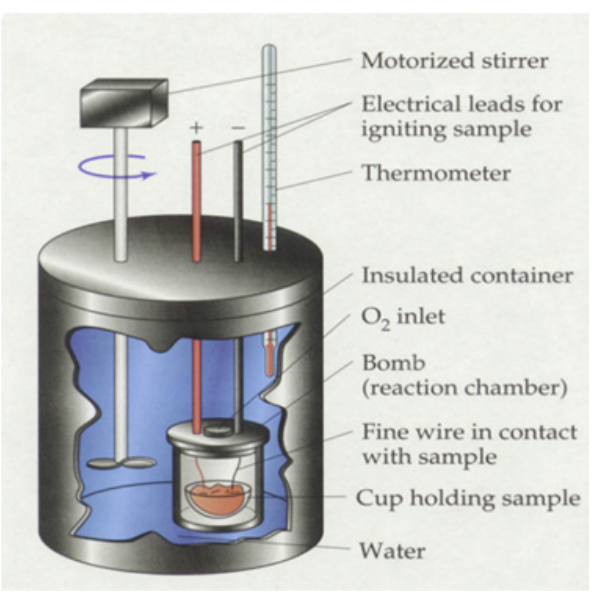

Figure 1. Schematic of adiabatic calorimeter.

$\left(\mathrm{V}_{\text {water }}=1.8 \mathrm{l}\right)$ which is used to determine the temperature variation and then the amount of heat released during combustion. Let $t_{i}$ be the initial temperature. After combustion, the temperature of the calorimeter increases and stabilizes at $t_{e}$.

$\mathrm{Q}$ (comb) is the heat generated by the reaction. This heat is absorbed by the complete calorimeter and reaction products present in the bomb. Neglecting the influence of these products to the high mass of the calorimeter and the water it contains.

The equation of calorific conservation gives: $\Sigma \mathrm{Qi}=0$.

$$
Q(\operatorname{comb})+(M * C(e a u)+C(c a l))\left(t_{e}-t_{i}\right)=0 .
$$

Heat capacities are determined by a constant volume. Solving this equation determines $\mathrm{Q}$ (comb) for $\mathrm{m} 1(\mathrm{~g})$ of product. The calorimeter calibration is made by the combustion of a product with known the calorific value [4].

\section{3) Moisture determination}

The fuel moisture is the water content of the fuel. Determining the moisture content is based on measuring the loss of mass of water in the fuel after drying in an oven to a constant mass [1].

\section{4) Ash determination}

Ash is mainly composed of inorganic materials. These materials do not burn, so do not contain energy. The ash content is measured trough the mass of the solid residue obtained after combustion of the organic compound in the following conditions: burning at a maximum temperature of $815^{\circ} \mathrm{C}$ until constant weight of the residue, the charging is done in cold and the heating regime is $30 \mathrm{~min}$ to reach $500{ }^{\circ} \mathrm{C}$, then 30 to 60 minutes to $815^{\circ} \mathrm{C}$ [2].

\section{5) Study of the influence of moisture and ash}

The experiments that were conducted showed that the calorific value is influenced by other parameters namely

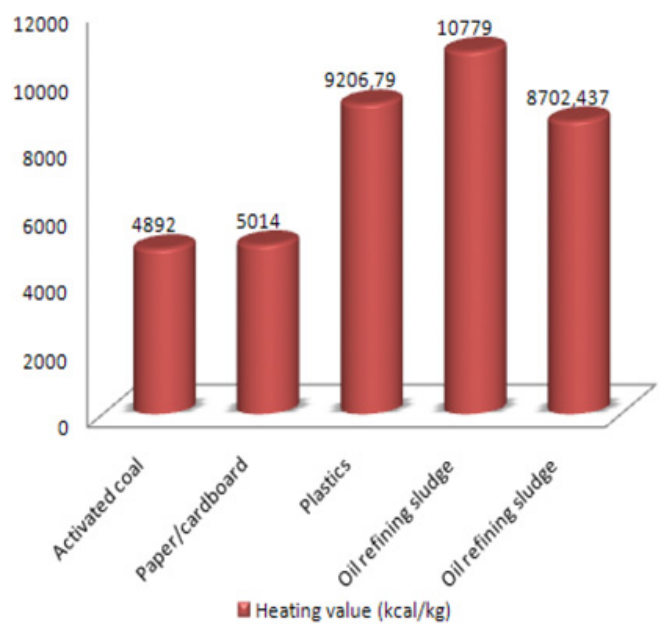

Figure 2. Heating value for different samples.

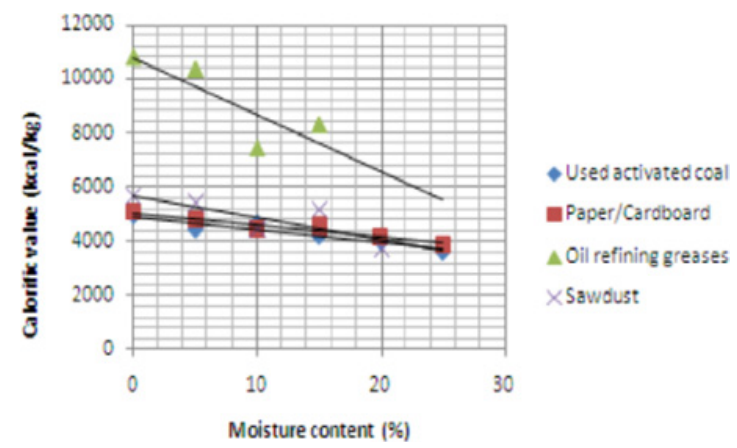

Figure 3. Effect of moisture on the heating value of different materials.

moisture and ash content. Therefore, It was necessary to study the evolution of the heating value in terms of these two parameters.

For tests related to the study of the influence of moisture, the heating value was determined for samples containing different percentages of moisture. Tests on the study of the influence of ash content on the calorific value is achieved by adding increasing amounts of an inert compound to the sample predried. The compound is $\mathrm{NaCl}$.

\section{II) RESULTS AND DISCUSSION}

\section{1) Heating value of fuels}

Results for the calorific value measurement of different samples are shown in Figure 2.

The calorific value (and thus the thermal energy contained in the fuel) depends on the fraction of organic matter contained in the fuel. This is why the calorific value of certain compounds is more important than others.

\section{2) Influence of moisture on calorific value}

Results are presented as curves of calorific value evolution in terms of moisture content (Figure 3).

In all three cases, the HV evolution in terms of moisture is significant. We note that the three representations have similar paces. Indeed, when moisture 
Table 1. Fuel mixture parameters spreadsheet.

\begin{tabular}{|l|c|c|c|c|c|c|}
\hline \multicolumn{2}{|c|}{ Raw materials parameters } \\
\hline Raw material & $\begin{array}{c}\text { weight } \\
(\mathrm{kg})\end{array}$ & $\begin{array}{c}\text { Moisture } \\
\text { content } \\
(\%)\end{array}$ & $\begin{array}{c}\text { Calorific value (in } \\
\text { terms of moisture } \\
\text { content })(\text { Kcal/kg) }\end{array}$ & $\begin{array}{c}\text { Ash content } \\
\text { on dry basis } \\
(\%)\end{array}$ & $\begin{array}{c}\text { Ash content } \\
\text { in the sample } \\
(\mathrm{kg})\end{array}$ & $\begin{array}{c}\text { Ash content } \\
\text { on raw material } \\
(\%)\end{array}$ \\
\hline Paper / Cardbord & 100 & 10 & 4578.7 & 16.5 & 14.85 & 14.85 \\
\hline Used Activated coal & 150 & 25 & 3695.25 & 34.6 & 38.925 & 25.95 \\
\hline Plastics & 250 & 0 & 9206.79 & 4 & 10 & 4 \\
\hline Greases & 50 & 20 & 6581 & 4.8 & 1.92 & 3.84 \\
\hline Sawdust & 20 & 12.7 & 4706.845 & 15.3 & 2.67138 & 13.3569 \\
\hline
\end{tabular}

\begin{tabular}{|c|c|c|c|}
\hline \multicolumn{4}{|c|}{ Mixture parameters } \\
\hline Total weight $(\mathrm{kg})$ & Moisture content $(\%)$ & Calorific value $(\mathrm{kcal} / \mathrm{kg})$ & Ash content $(\%)$ \\
\hline 570 & 13.54 & 5753.717 & 12.39938 \\
\hline
\end{tabular}

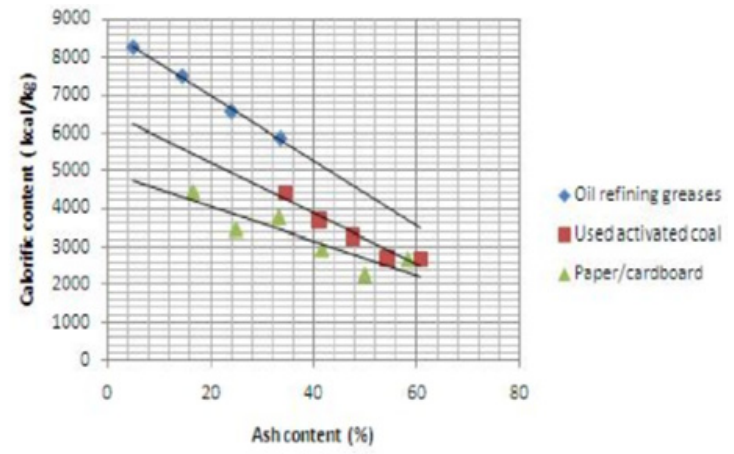

Figure 4. Effect of ash content on the HV of different materials.

increases the HV decreases: the reduction of heat can be attributed to the dissipated energy to evaporate water.

Such curves will eventually determine the calorific value of a sample with a known humidity without having to measure it experimentally.

\section{3) The influence of ash content on the HV}

Results are shown in Figure 4.

The curves shape shows that the LHV (lower heating value) decreases when the ash content increases, it is due to the fact that the samples with an interesting heating value have low mineral content (ash) and a high organic content.

\section{4) Simulation of the calorific value of waste mixture}

The curve equations previously obtained will be useful during the fuel formulation using a tool specially developed in order to determine the mixture parameters that would make the alternative solid fuel. Spreadsheets (computer program able to manipulating spreadsheets) are suitable for automatic processing of data obtained in previous tests. This will allow us to move from managing simple databases to produce graphs (spreadsheet-graph).

\section{EXAMPLE}

Data concerning raw materials is displayed on the Excel spreadsheet as shown in Table 1.

\section{Heating/Calorific value of activated coal in terms of moisture content}

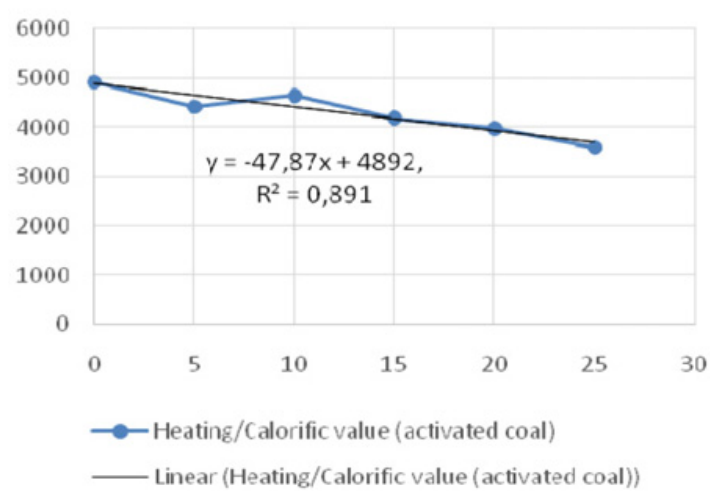

The basic data is the dried sample mass, the moisture content and the ash content of the dried sample. The spreadsheet can compute the HV in terms of moisture content based on equations obtained during the evaluation of humidity on the calorific value. For example: the linear equation that was obtained during the evaluation of the effect of moisture on the calorific value of activated coal (in this case the equation is $y=-47,87 x+4892$ where $y$ is the heating value and $\mathrm{x}$ is the moisture content value) is the one used in order to determine the heating value once we know the moisture content value.

Knowing the heating value evolution of each component in terms of the moisture and the ash content, the heating value of the mixture is easily determined.

\section{CONCLUSION AND OUTLOOK}

The study conducted in this work proved that industrial waste fulfills very ambitious criteria regarding their use as alternative fuels. Some of them are even having some close characteristics to fossil fuels. Mathematical models are more likely to use in order to formulate alternative fuels of different compositions. Studies to come will take interest on the study of gaz emissions during combustion. 


\section{References}

[1] Mesure des caractéristiques des combustibles bois (ADEME Critt Bois- Fibois - CTEA) Juillet 2001.

[2] Criteria for solid recovered fuels as a substitute for fossil fuels- a review. Michael Beckmann, Martin Pohl, Daniel Bernhardt and Kathrin Gebauer. Waste Manag Res 2012 30: 354 originally published online 30 March 2012.
[3] Synthetic fuel for imitation of municipal solid waste in experimental studies of waste incineration Original Research Article.

Chemosphere, Volume 44, Issue 5, August 2001, Pages 1071-1077.

Sukrut S. Thipse, Chad Sheng, Michael R. Booty, Richard S. Magee, Edward L. Dreizin

[4] Thermique appliquée aux fours industriels, Tome 1. Notions fondamentales / Werner HEILGENSTAEDT. 